\title{
PLANNING OF TUNNELING PROJECTS USING COMPUTER SIMULATION AND FUZZY DECISION MAKING
}

\author{
Moatassem ABDALLAH ${ }^{\mathrm{b}}$, Mohamed MARZOUK \\ ${ }^{a}$ Department of Civil and Environmental Engineering, University of Illinois at Urbana-Champaign \\ (UIUC), Illinois, USA \\ ${ }^{b}$ Structural Engineering Department, Faculty of Engineering, Cairo University, Giza, Egypt
}

Received 23 Jul. 2011; accepted 8 Dec. 2011

\begin{abstract}
Tunnel construction is one of the important infrastructure projects, which is vital for enhancing the transportation networks, especially in congested cities. Tunnel projects are characterized by long durations, large budgets, complexities, repetitive construction tasks, risks, and uncertainties. Several construction techniques have been developed in the tunnel construction industry to improve the constructability of tunnels and decrease the impact on surrounding structures. This paper presents a framework for planning tunnel construction using computer simulation. The proposed tool aids contractors in estimating the required time and cost for construction. Five tunnel construction techniques have been considered in the development of this tool with different ground supporting techniques. The proposed framework consists of three modules: (1) tunnel analyzer module, (2) simulation module, and (3) decision support module, and is capable of selecting the best construction technique using fuzzy group decision-making method based on time, cost and other selection criteria that could be defined during the decision-making phase. This decision method ranks alternatives based on a group of experts and a predefined set of criteria. Numerical examples are introduced to illustrate the capabilities of the proposed framework.
\end{abstract}

Keywords: planning; tunnel construction techniques; computer simulation; cost and scheduling; fuzzy decision-making.

Reference to this paper should be made as follows: Abdallah, M.; Marzouk, M. 2013. Planning of tunneling projects using computer simulation and fuzzy decision making, Journal of Civil Engineering and Management 19(4): 591-607. http://dx.doi.org/10.3846/13923730.2013.793608

\section{Introduction}

Construction of tunnels has gone through several phases of development. Decades ago, tunnel construction included mainly manual excavation and small sized equipment, which are used to carry out different tasks in the construction operation. Afterward, it has gone through different phases and developments of techniques until it reached currently, a high degree of mechanization including: cranes, pile drilling rigs, trench cutter machines, concrete/bentonite pumps, trucks, mixers and/or tunnel boring machines (TBM). At the beginning of construction, tunnel construction included fewer tasks, which were manageable to be planned with traditional construction techniques. However, the advancement in tunnel construction has increased the sophistication, interconnection between activities, and uncertainties in the construction operation, which can lead to deviation from original work plans. Traditional planning techniques, such as preceding diagram method (PDM), critical path method (CPM), Program evaluation and review techniques (PERT) or line of balance method (LOB) are considered practical techniques for scheduling construction operations. However, they do not plan tunnel projects efficiently with the inherited sophistications and uncertainties in tunnel construction. In addition, they do not provide the efficient use of available resources in the construction operation of tunnels. Furthermore, the new techniques in construction of tunnels have improved constructability through segmental operation, which made the construction to be carried out in a cyclic manner (Halpin, Riggs 1992; Banks et al. 2000; Marzouk 2010).

Computer simulation has proved its efficiency in planning construction projects for the following reasons: (1) the availability of several probability density functions, which account for uncertainties that might occur during construction, (2) taking into consideration the interaction among available resources

Corresponding author: Mohamed Marzouk

E-mail: mm_marzouk@yahoo.com 
during the planning phase, and (3) the application of WHAT-IF analysis and sensitivity analysis in planning of construction projects to identify factors that might affect the construction operation. Several efforts have been conducted in planning of construction projects using computer simulation. These studies include concrete operations (Hassan, Gruber 2008), bridge decks construction (Marzouk et al. 2006, 2008a), earthmoving operations (Marzouk 2002), and tunnel constructions (Al-Battaineh et al. 2006; Tanaka 1993). Limited studies have been conducted for simulating the construction of cut-and-cover tunnels with different supporting techniques. However, few studies have been carried out for modeling tunnels with circular and horse shoe cross-sections (AbouRizk et al. 1999; Loannou, Likkhitruangslip 2005). A special purpose simulation template for shielded tunnels was developed using Simphony, where the user is capable of adding as many tunnel sections to the model based on soil properties in each section. In addition, the developed simulation model was used to conduct a comparison between small and large tunnel diameters in terms of productivity. The developed simulation model was tested for different soil types and it showed that as the stiffness of soil increases, the tunnel advancement rate decreases (AbouRizk et al. 1999).

Several techniques have been developed to model multicriteria decision-making (MCDM). These techniques include utility-theory method (Keeney, Raiffa 1993), analytical-hierarchy process (Saaty 1980, 1982), superiority and inferiority method (Marzouk 2008; Xu 2001), ELECTRE III (Marzouk 2011) and fuzzy trade-off evaluation method (Nishizaki, Seo 1994). Each method has its advantages and drawbacks in dealing with the problem under consideration. Such techniques lack the ability to model the uncertainties which are inherited in many of the decision-making problems. Fuzzy numbers have the ability to model uncertainties in multicriteria decision-making (MCDM). Several methods have been introduced for ranking alternatives based on fuzzy numbers (Lee-Kwang, Lee 1999; Modarres, Shadi-Nezhad 2001; Zhang, Lu 2003). Immense studies have been conducted in decision making to select the best alternative that best fits the designated goals. These studies included: assessing intangible aspects of technical innovation in construction (Skibniewski, Chao 1992), determination of bid(s) markup using utility-theory model (Hassan, Gruber 2008), selection of best construction contractor (Alsugair 1999), selection of finalists for a director position (McIntyre et al. 1999), obtaining sustainable residential building based on the acceptable level of environmental impact and socioeconomic characteristics of residential buildings (Seo et al. 2004), and selecting the most appropriate contractor for delivering a project (Singh, Tiong 2005). This paper presents a framework that aids contractors in planning tunnel projects using computer simulation. It provides two main functions: (1) estimating time and cost required for construction of tunnels, and (2) selecting best construction alternative/technique among a set of different construction options, considering five tunnel construction techniques. This paper provides an overview of the developments made in the proposed framework.

\section{Construction of tunnel projects}

Tunnels are usually constructed in crowded cities for the purpose of improving transportation networks by decreasing time required to move from one place to another. Tunnels can be classified into two groups based on the cross-sectional shape: rectangular crosssection and circular cross-section. The former group is essentially constructed using cut-and-cover technique, whereas, the latter group is constructed using TBM. The following subsections describe these techniques, which are used in tunnel construction projects.

\subsection{Cut-and-cover techniques}

Tunnel construction using cut-and-cover techniques offer an alternative to boring machines, where a trench of required depth and width can be excavated from the surface. The construction of cut-and-cover tunnels in its simplest form includes: trench excavation, building tunnel structure, backfilling tunnel trench, and the surface restoration (EOT, U.S.DOT 2008). Supporting of ground soil along with maintaining existing surface, underground facilities, and services increase the complexity of tunnel projects. The key aspect to the various cut-and-cover methods lies in supporting the vertical sides of tunnel construction. Several techniques have been developed in construction of cut-andcover tunnels, which are categorized based on ground supporting methods; these techniques include: cutand-cover using diaphragm walls, cut-and-cover using secant pile walls, cut-and-cover using soldier piles and lagging, and cut-and-cover using steel sheet pile walls. Despite the fact that cut-and-cover construction techniques are one of the oldest techniques that are used in construction of tunnels, it is still being used in construction due to the following characteristics (EOT, U.S.DOT 2008):

- it is usually cheaper and more practical than other underground tunneling, especially for tunnels with small lengths;

- cut-and-cover method is considered as an appropriate tunneling technique for construction of tunnels with small depths;

- the risk that is taken by the contractor in the construction of tunnels using this method is considered as small, relative to other construction techniques; 
- it may cause interference with traffic and other urban activities, but this disturbance is decreased by construction of the tunnel top slab after excavation or by using temporary decking over the excavation. This temporary deck is left in place, where construction activities can be carried out underneath until reaching final backfilling and surface restoration.

Detail description of cut-and-cover using diaphragm walls and cut-and-cover using secant pile walls can be found elsewhere (Abdallah 2008; Marzouk et al. 2008b, 2009). Cut-and-cover using soldier piles and lagging technique is considered to be one of oldest retaining systems that are commonly used in supporting deep excavations. Soldier piles and lagging walls are constructed in a cyclic manner by placing soldier piles at regular intervals $(2-4 \mathrm{~m})$, then excavating and installing lagging between soldier piles. Soldier piles and lagging walls are the most inexpensive systems compared to other retaining walls (FORASOL 2008). Although, soldier piles and lagging walls are very easy and fast to construct, they have the following disadvantages (Henery Drilling 2011):

- primarily limited to temporary construction;

- inapplicable when ground water table is near to ground surface;

- significant surface settlements in case of poor backfilling;

- less stiffness than other retaining systems;

- difficult to control soil movements as the flange of soldier piles are embedded beneath subgrade.

Tunnel construction with cut-and-cover method using soldier piles and lagging is performed by dividing tunnel length into equal segments $(20 \sim 30 \mathrm{~m})$. It involves eight main processes (Land Transport Authority 2004): (1) segments preparation, (2) installing of soldier piles and excavation, (3) construction of anchors, (4) excavation, (5) construction of bottom slab segments, (6) construction of side wall segments, (7) construction of top slab segments, and (8) segments backfilling (see Fig. 1). The first process of segments preparation involves surveying to coordinate the position of each segment according to the tunnel path, and excavation and soil leveling till the top level of soldier piles. The second process of installing of soldier piles and excavation is started by installing soldier piles into the ground, and then excavating the soil between soldier piles to install timber lagging. The installation of soldier piles is executed by first drilling the soldier pile hole using a pile drilling rig, then placing soldier piles into the holes. Once the soldier pile is installed into position, concrete can be poured into the bottom part of the hole. Then, backfilling the rest of the drilled hole is performed. This operation is repeated to install all soldier piles in the segment.
The third process of construction of anchors is started by drilling the anchor hole using the anchor drilling rig. Then, a wire bundle is installed into the anchor hole. As such, the anchor hole can be filled with cement. Once the cement is settled, the grout can be pumped into soil behind the anchor to stick it with soil and increase its strength. After settlement of grout, the anchor can be tensioned to connect the anchor force to the soldier pile. The fourth process of excavation is started by excavating soil between each two soldier piles and installing timber lagging between them. During the excavation between soldier piles and installation of timber lagging, the excavation in the center of segment can be executed separately. After finishing the previous tasks, the excavation for the rest of the segment can be executed.

The fifth process of construction of the bottom slab segments is started by excavating the soil till the base of the plain concrete. Then, pouring of plain concrete takes place. After that, the reinforcement bars, which are either fabricated on-site or at off-site workshop, are placed to form the reinforcement cage of the bottom slab segment of the tunnel. Then, forms can be erected and water-stop can be installed. At this stage, concrete is ready to be poured and cured, and finally, forms can be removed. The sixth process of construction of side walls segments is started after removal of forms of the bottom slab. The walls of a segment are constructed by fixing the steel reinforcements in the tunnel sides to form the steel cage. Once the steel is fixed, forms of the tunnel walls can be erected (see Fig. 2). After assembling of forms, concrete can be poured and cured, and forms can be removed when concrete gains enough strength that allows the construction of the next process. The seventh process of construction of top slab segments is started by shuttering of forms for the top slab to provide support for concrete, while achieving sufficient strength to support its own weight and loads. The final process of segments backfilling is executed after removing the forms of the tunnel top slab. The tunnel may be backfilled with clean soil or by the excavated soil according to its quality and specifications. These processes are repeated for each segment.

Cut-and-cover using steel sheet pile walls technique involves the use of sheet pile walls, which are essentially rows of interlocking vertical pile segments that are installed to form an efficiently straight wall with a planned dimension sufficiently large enough to retain soil. Steel sheet pile walls are used in soft grounds specially when there is danger of bottom heave in soft clay soil or in the case of sand. Tunnel constructions using steel sheet pile walls have the following advantages: suitable for various service conditions, easy speed driving of sheet pile walls and easy storage and shipping. On the other hand, steel sheet piling have the following disadvantages: causes 


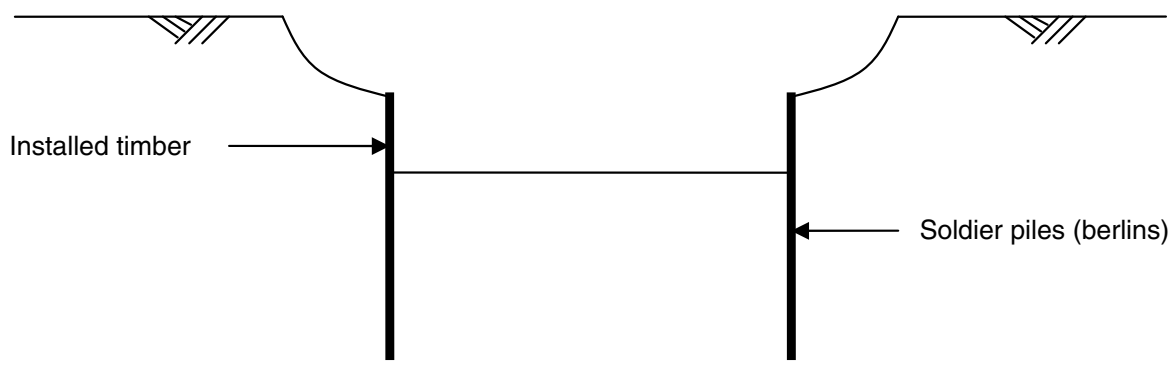

Processes 1 and 2: Segment preparation, installing of berlins and excavation

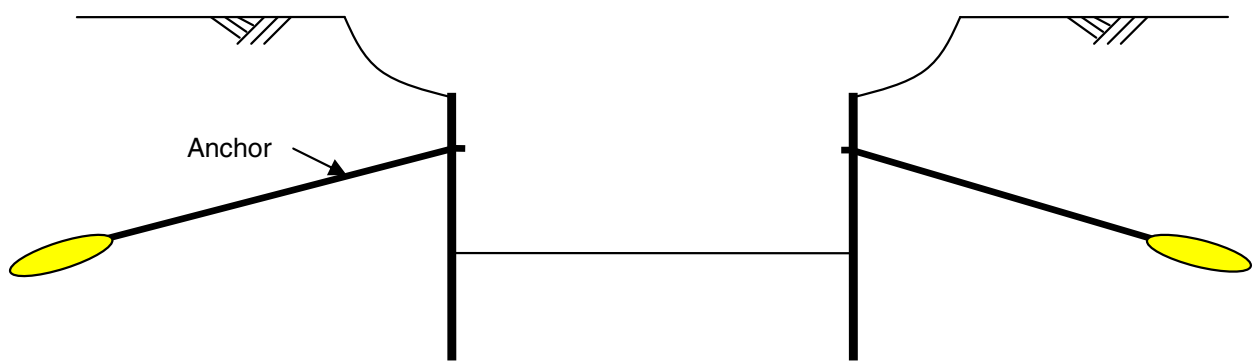

Processes: 3 and 4: Construction of anchors and excavation

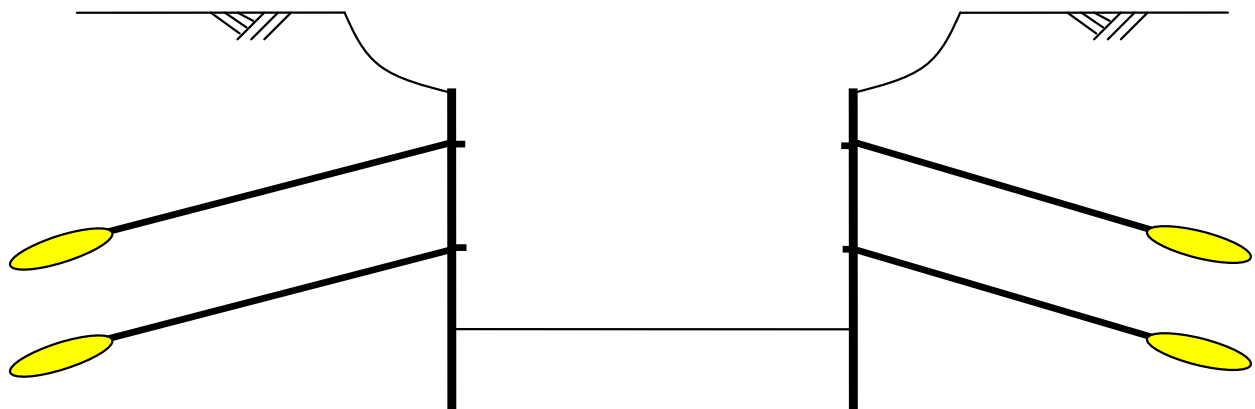

Processes 3 and 4: Construction of anchors and excavation



Processes 5, 6, 7 and 8: Construction of tunnel bottom slab, side wall, top slab, and backfilling

Fig. 1. Construction processes of cut and cover method using soldier piles and lagging

noise and vibrations when the vibratory-hammer is utilized, involves high cost relative to other retaining methods, can be used only when the sheet piles are not required to be driven deeply into the ground, permits large movements in weak soils, and requires effective de-watering since it cannot provide a watertight boundary (Deep Excavation 2011).

The tunnel construction with cut-and-cover method using steel sheet pile walls is performed by dividing the tunnel length into equal segments $(20 \sim 30 \mathrm{~m})$. It involves eight main processes (Land Transport Authority 2004): (1) segments preparation, (2) installing of sheet piles, (3) dewatering and excavation, (4) construction of anchors and installing of steel anchor connecting beams, (5) construction of the bottom slab segments, (6) construction of the side wall segments, (7) construction of the top slab segments, and (8) segments backfilling. All processes 


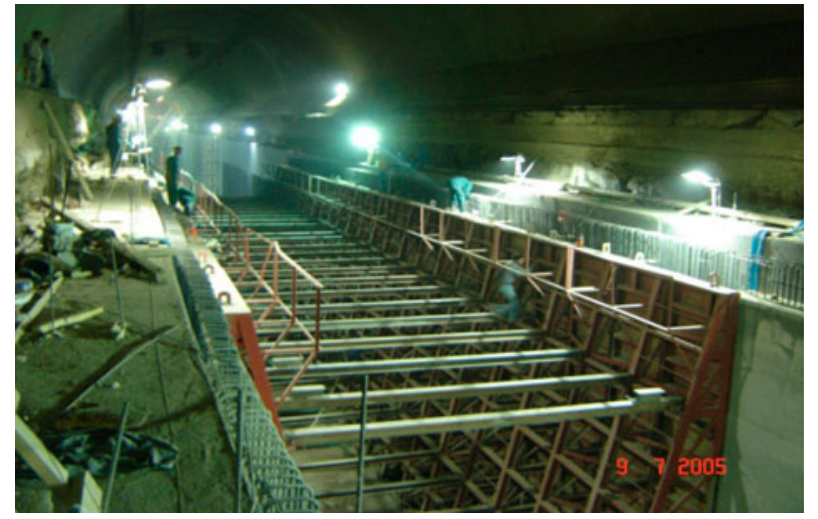

Fig. 2. Side forms of tunnel segment

are similar to tunnel construction with cut-and-cover method using soldier piles and lagging processes except for the second process of installation of sheet piles. This process starts by locating and placing of a beam into the ground to set out the position of the sheet pile wall. Then, the piling rig/vibrator lifts up the first sheet pile and drives it into the ground, leaving about 1 meter length of the sheet pile above the ground level. After that, the piling rig/vibrator drives the second sheet pile into the ground, where the second sheet pile interlocks with the first one. This process is repeated till installation of all sheet piles (see Fig. 3).

\subsection{Segmental tunneling using slurry TBM}

Circular tunnels are usually constructed using closed/ open face TBM. A TBM is a complex set of equipments, assembled to excavate a tunnel. It is manufactured to bore through hard rocks or sand layers and any type of soil. There are several types of closed face TBM s based on soil conditions and tunnel lining. In case of hard soil or rock, machines are built to advance through hard material that is usually selfsupported, and have tools that are made for breaking the hardest rocks. The excavation is carried out at atmospheric pressure, and the extraction of material is performed using trains, trucks or conveyor belts. In case of soft soils, excavation is executed through a turning cutting wheel. The excavated material is

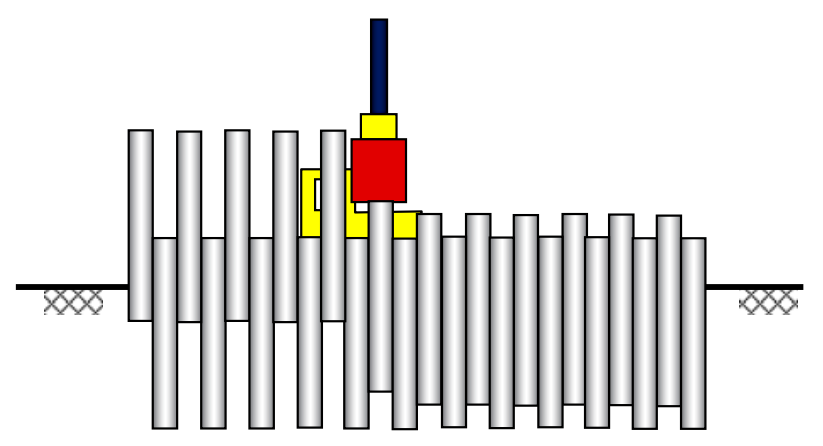

Fig. 3. Construction sequence of steel sheet pile walls usually handled by a hydraulic transportation system. This is done by using either water or bentonite as a transportation medium. The lining of the tunnel may be in-situ pressed concrete lining which is poured during the excavation of the tunnel, or pre-cast concrete segments which are installed during excavation of the tunnel. The segmental tunneling method using closed face TBM is used for circular crosssection. It is worth noting that, the construction of tunnels using in-situ pressed concrete lining gives slow productivity, which is not consistent in urban and crowded areas. The slurry shield has developed in recent decades for managing instability of excavation profile in unfavorable geotechnical conditions. With slurry TBM, the unstable/soft ground at the front is supported by liquid mixture (bentonite or water) under increased pressure generating a steady counter pressure. The construction of circular tunnels using slurry TBMs has the following advantages: high progress rate, especially in soft ground soil, continuous operation, less noise and disturbance to surrounding structures, in addition to being the best way for constructing deep and long tunnels. On the other hand, slurry TBMs have the following disadvantages: fixed circular geometry, limited flexibility in response to extremes of geologic conditions, longer mobilization time, and higher capital costs.

The construction sequence of circular tunnels using slurry TBM is divided into four processes: soil injection, TBM setup, tunnel construction, and TBM dismantle. The first process of injecting soil is executed for the break in and break out regions of the TBM, as the soil in these two regions may cause the boring machine to deviate from the tunnel path in case of weak soil. In addition, segments in the break in and break out points have to be constructed in stiffer soil. This process is executed by locating injecting points in the break in region using survey, and then drilling the located points and injecting them with cement. This process is repeated till injecting all points in the break in region are completed. After that, laborers and equipment are moved to the break out point to inject soil with cement using the same sequence as of the break in region. It should be noticed that, this process is not necessary in case of hard or stable soil. The second process, TBM setup, can be started while injecting the soil of break in region with cement. This process is started by constructing the buttress wall that will be used to support the boring machine to get into soil, and after that, the TBM and its components can be installed. The TBM setup includes installing of steel shield, back-up tail, separation plant, feed pump, and slurry pump.

The third process, tunnel construction, starts after the settlement of cement in the break in region and completion of the second process. It begins with installing temporary steel segments between the 
machine and the buttress wall. Then, the boring machine can start excavation of soil. During soil excavation, the excavated material is moved to the shaft using a transportation system, either by using water or bentonite. The transportation medium is pumped to the tunnel face from the start shaft by one or several feed pumps in a feed line. The transportation medium is utilized to stabilize and support the tunnel face and to facilitate the excavation process. The mixture of soil and transportation medium is exhausted out of the excavation chamber through the slurry line and conveyed to the separation plant. To prevent the slurry line from getting blocked, any major pieces of rock are pulverized by the cone crusher in the working chamber before being passed into the slurry line. In the separation plant, the transportation medium is separated from the loose soil using screens, cyclones and centrifugal pumps if necessary. Efficient separation means that a large proportion of the medium can be treated and sent back into transportation circuit. The separated soil is then loaded into trucks to be transported to the dumping area.

When the advancement of the machine reaches a distance equal to the length of a ring, the excavation stops and the pushing jacks are retrieved. Then a temporary steel ring is installed and the pushing arms are extended to resume excavation. This sequence is repeated till the last temporary steel ring is installed in front of the soil. After the machine reaches a distance equal to the length of a ring, the excavation stops and the pushing jacks are retrieved. Then, a pre-cast concrete ring which consists of number of segments is installed. Subsequently, the pushing arms are extended once again in full contact with the concrete ring to resume excavation. During excavation, a grout is pumped to fill the space generated between the precast concrete ring and the soil. The cycle of excavation and ring erection is repeated as the TBM advances to form the lining of the tunnel.
During soil excavation, the pre-cast concrete segments are loaded into the TBM's train and then transported to the tunnel face. After installing the segments, the train is transported to the shaft to get the next segments. The TBM has to follow the pass carefully from the driving to the receiving shafts using a laser guiding system. The laser guiding system determines the orientation of the machine head to make any needed corrections in the tunnel path. During the excavation of the tunnel, the extension of the articulated jacks allows the TBM to turn and advance forward in the direction of the tunnel designed axis. After installing sufficient number of pre-cast concrete rings (10-15 rings), the buttress wall can be dismantled. As such, the boring machine can be jacked on the installed pre-cast concrete rings based on the own weight of the installed rings and grout around them. The final process of TBM dismantle is executed when the TBM reaches the receiving shaft. It starts by dismantling the boring machine with its components. Finally, the tunnel can be cleaned.

\section{Proposed simulation framework}

The proposed simulation framework aids contractors in planning tunnel constructions. It performs two main functions: (1) planning and analyzing tunnel construction and (2) selecting the best construction alternative based on pre-defined criteria. The framework consists of three main components: tunnel analyzer module, simulation module, and decision support module. Figure 4 depicts a schematic diagram for the proposed framework that shows the interaction between its main components. Detail description of the framework can be found elsewhere (Abdallah 2008). The following subsections describe in detail the components of the framework.

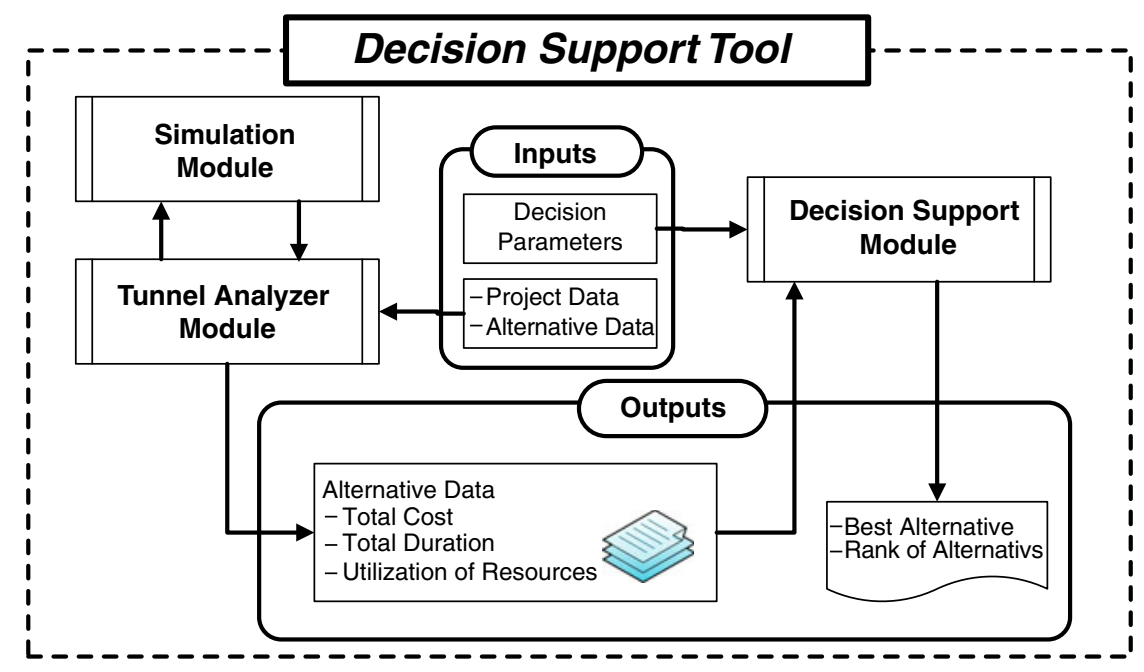

Fig. 4. Interaction among framework components 


\subsection{Tunnel analyzer module}

Tunnel analyzer module is considered to be the interface and coordinator of the planning function for the framework. Tunnels are broken down into zones taking into consideration the following factors:

- Project is divided into a number of zones, where the construction method is assigned and defined in each zone;

- The assigned resources in each zone are defined independently of the other zones (i.e. for a project that is divided into two zones, a construction method is defined in each zone and resources are assigned independently for each construction zone even with the same construction method);

- General sequence of construction is defined for the project. For example, two construction zones that are constructed with the same/different construction method and are required to be executed simultaneously or successively. Each zone is defined separately with a specific relationship between them (Finish to Start or Start to Start with lag).

The procedure followed by tunnel analyzer module for planning tunnels can be summarized as follow:

- Assigning project general data, such as number of working hours per day, number of working days per week, project start date, number of zones in the project, and indirect cost required for the project. Also in this stage, the user is required to set number of simulation runs which will indicate the accuracy of the simulation output;

- Defining the construction method for each zone. Then, assign the required data for each zone including: general data of the assigned construction method, duration of tasks and corresponding probability density function (e.g. beta, erlang, exponential, gamma, normal, pert, pertpg, scaled beta, triangular, and uniform), required number of resources for each task, available resources in each zone, labor and equipment rates, and materials costs. Then, the module saves the collected data and sends it to the simulation module;

- Subsequently, simulation module is triggered to estimate the duration and utilization of resources for each zone. Then, simulation outputs are sent to tunnel analyzer module in order to calculate project execution time and costs;

- Finally, tunnel analyzer module presents the estimated data to the user.

Tunnel costs are classified into direct cost and indirect cost. The direct cost involves materials, labor, and equipment costs, while indirect cost involves items which depend on project duration and others items that are independent of project execution time. Material costs are calculated by summing up costs of each item used in project construction, such as concrete quantities, steel bars, forms, pipes, bentonite, and so on. Labor and equipment costs are calculated using Eqns (1) and (2). Indirect cost and project total cost are calculated using Eqns (3) and (4):

$$
\begin{aligned}
\mathrm{TL} & =\sum_{i=1}^{m} \sum_{j=1}^{n} \mathrm{LUC}_{j, j} \cdot \mathrm{LUT}_{i, j} \cdot \mathrm{ZD}_{i} ; \\
\mathrm{TE} & =\sum_{i=1}^{m} \sum_{j=1}^{n} \mathrm{EUC}_{j, j} \cdot \mathrm{EUT}_{i, j} \cdot \mathrm{ZD}_{i},
\end{aligned}
$$

where TL - total labor costs; TE - total equipment costs, $\mathrm{m}$, number of zones; $n$, number of resources in each zone; LUC, labor unit cost/unit time; EUC, equipment unit cost/unit time; LUT, utilization for specific labor crew (time elapsed for utilizing a specific labor crew per zone duration, the developed simulation module calculates a percentage, where a labor crew is utilized in the construction of each zone); EUT, utilization for specific equipment (time elapsed for utilizing a specific equipment per zone duration, the developed simulation module calculates a percentage, where an equipment is utilized in the construction of each zone); and $\mathrm{ZD}$, zone duration.

$$
\mathrm{TIC}=\sum \mathrm{TDIC} \cdot \mathrm{PD}+\sum \mathrm{TIIC}
$$

where TIC - total indirect cost; TDIC - time dependent indirect costs; PD - project duration; TIIC - time independent indirect costs.

$$
\mathrm{PC}=\mathrm{TM}+\mathrm{TE}+\mathrm{TL}+\mathrm{TIC},
$$

where PC - project cost and TM - total material costs.

\subsection{Simulation module}

Simulation module is responsible for estimating total duration of construction and utilization of resources. The proposed module uses STROBOSCOPE as a general purpose simulation language (Martinez 1996). It is developed using Microsoft Visual Basic 6.0 language to control and enter data to STROBOSCOPE simulation engine. Five models have been developed using STROBOSCOPE simulation language in the simulation module as listed in Table 1. These simulation models were built based on construction sequence and available simulation elements to mimic the different tunnel construction techniques described earlier.

The process followed by the simulation module to estimate construction duration and resource utilization is summarized as follows:

Simulation module receives project data from tunnel analyzer module, and then, it depicts the model 
Table 1. Developed simulation models for tunnels construction

\begin{tabular}{ll}
\hline Model name & \multicolumn{1}{c}{ Description } \\
\hline Cut \& cover1 & $\begin{array}{l}\text { Tunnels construction by cut-and-cover } \\
\text { method using diaphragm walls }\end{array}$ \\
Cut \& cover2 & $\begin{array}{l}\text { Tunnels construction by cut-and-cover } \\
\text { method using secant pile walls }\end{array}$ \\
Cut \& cover3 & $\begin{array}{l}\text { Tunnels construction by cut-and-cover } \\
\text { method using soldier pile and lagging wall } \\
\text { Tunnels construction by cut-and-cover } \\
\text { method using steel sheet pile walls }\end{array}$ \\
TBM & Segmental tunneling using slurry TBM \\
\hline
\end{tabular}

that represents the construction technique for each zone from models that are stored in the simulation module's library. Subsequently, each model is fed by its data (general data, duration of tasks, required and available resources, and number of replications) to generate the simulation model that represents the project described in tunnel analyzer module:

- STROBOSCOPE is triggered to run the generated model(s) in order to estimate total duration and utilization of resources in each zone;

- The output data are transferred to tunnel analyzer module to perform total project duration and cost calculations.

Developing a simulation model for construction of tunnels by cut-and-cover method using diaphragm walls involves the following assumptions:

- tunnel width is constant along its length;

- the tunnel is divided into zones (inlet, body, and outlet), which are divided into a number of segments with equal lengths;

- the widths of primary and secondary diaphragm trenches are constant;

- inlet, body, and outlet zones of the tunnel are represented by the same model, but with different input data (i.e. for the inlet and outlet zones, they are represented by the same developed model, but the durations for tasks of the top slab segments are assigned with zero values);

- in case of constructing a plug to save the surrounding structures from dewatering problems, guide walls and diaphragm trenches of the cutting wall are constructed first (i.e. cutting walls are constructed before the side diaphragm walls of the tunnel).

Cut-and-cover using diaphragm walls method involves eight processes: (1) segments preparation, (2) construction of guide walls, (3) construction of diaphragm walls, (4) construction of plug and dewatering, (5) construction of top slab segments, (6) construction of bottom slab segments, (7) construction of un-casted top slab segments, and (8) segments backfilling. Table 2 lists resources needed for developing the model of cut-andcover method using diaphragm walls. Table 3 lists input parameters of cut-and-cover method using diaphragm walls. Figure 5 depicts elements of the simulation model that represent cut and cover using diaphragm walls. Resources, listed in Table 2, are allocated in queues and filled with available number of resources. Each Combi activity draws the required number of resources from the needed queues in order to be executed.

The process of segments preparation consists of two tasks: (1) segment survey, and (2) general excavation and leveling for segment. This process is repeated for each segments of the tunnel. It should be noted that: dummy queues, which are utilized in developing the model, are used to maintain the logic flow and dependency between activities. After finishing the first process, the dummy queue, named "L02," and Combi logic activity, named "Logic02" with zero duration, are used to add the number of guide walls needed for constructing cutting wall (if needed). The second

Table 2. Resources used in cut-and-cover method using diaphragm walls model

Labor Concrete crew - formwork crew reinforcement crew - chiseler crew - survey crew - insulation crew.

Equipment Excavator - loader - compactor - crane concrete pump - trench cutter - injecting machine - well point machine.

Materials Guide wall form - top slab segment form bottom slab segment form - un-casted top slab segment form.

Table 3. Input parameter of cut-and-cover method using diaphragm walls model

\begin{tabular}{|c|c|}
\hline Parameter & Description \\
\hline NS & Number of segments in tunnel zone \\
\hline NGWPS & Number of guide walls per segment \\
\hline NDWPS & Number of dewatering wells per segment \\
\hline NDWPGW & $\begin{array}{l}\text { Number of diaphragm wall trenches per each } \\
\text { guide wall }\end{array}$ \\
\hline NDW & $\begin{array}{l}\text { Total number of reinforced diaphragm wall } \\
\text { trenches (without cutting wall) }\end{array}$ \\
\hline NDP & Total number of dewatering well points \\
\hline NIPPS & Number of injecting points per segment \\
\hline NGWPCW & Number of guide walls in each cutting wall \\
\hline NTSS & Number of tunnel top slab segments \\
\hline NBSS & Number of tunnel bottom slab segments \\
\hline NRTSS & Number of un-casted tunnel top slab segments \\
\hline A & $\begin{array}{l}\text { Lag between the third and fifth processes } \\
\text { (represented by number of segments) }\end{array}$ \\
\hline $\mathrm{B}$ & $\begin{array}{l}\text { Lag between the fifth and sixth processes } \\
\text { (represented by number of segments) }\end{array}$ \\
\hline
\end{tabular}




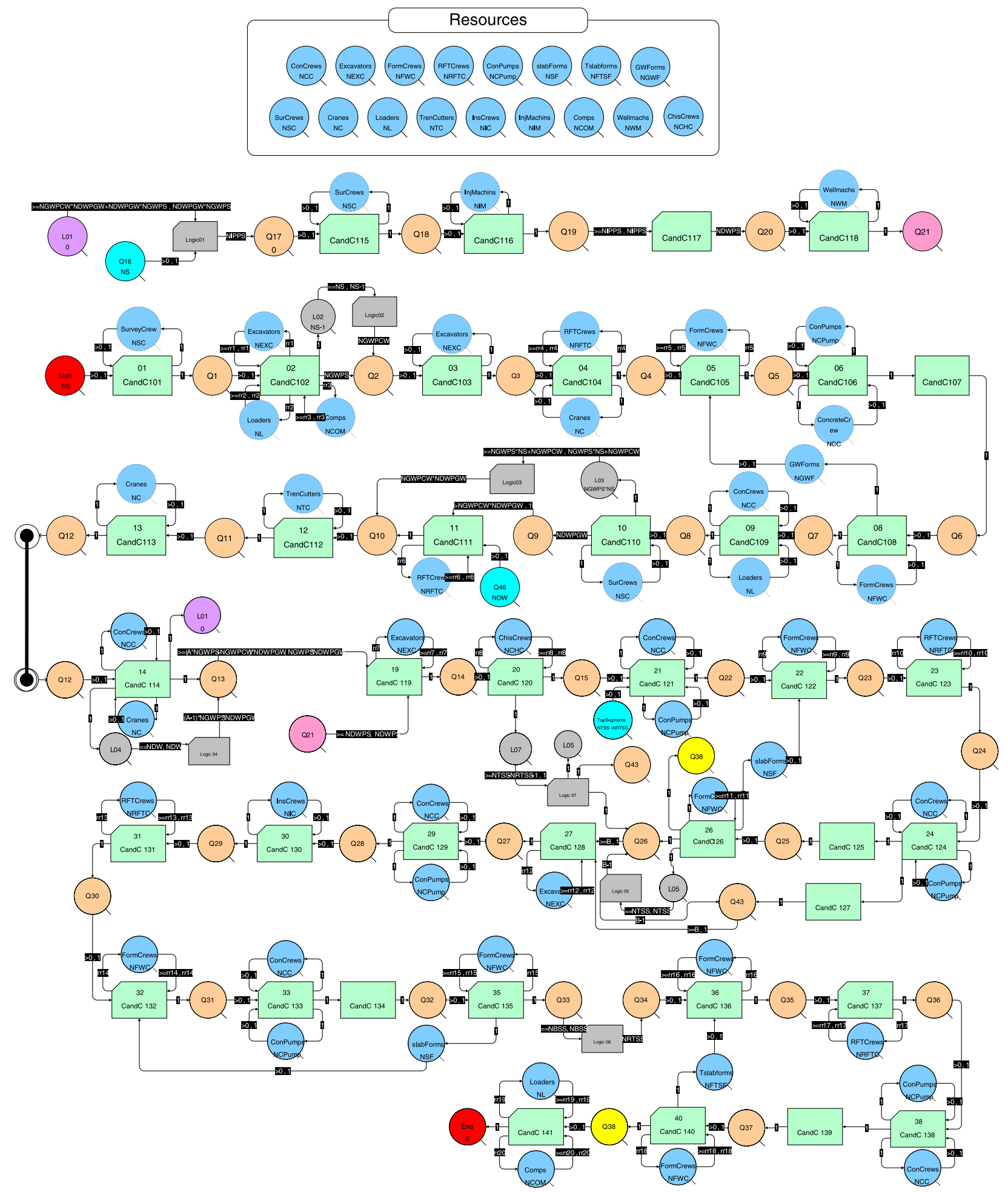

Fig. 5. Simulation model of cut and cover method using diaphragm walls

process, named construction of guide walls, consists of eight activities: (1) excavation, (2) steel work, (3) shuttering of forms, (4) concrete pouring, (5) concrete curing, (6) removal of forms, (7) backfilling, and (8) paneling and marking. After finishing each segment of the first process, the last activity in first process sends number of guide walls in one segment to the first dummy queue in the next process. It should be noted that, the second process is repeated for each guide wall in a zone.

After finishing the second process there is a dummy queue, named "L03", and Combi logic activity, named "Logic03" with zero duration, used to add the number of diaphragm wall trenches needed for 
construction of cutting wall (if needed). The third process, named construction of diaphragm walls, consists of four tasks: (1) preparing and fixing of steel cage, (2) trench excavation, (3) position steel cage into excavated panel, and (4) concrete pouring. After construction of each guide wall, second process, it sends number of diaphragm trenches in one guide wall to dummy queue, named "Q9", to be the initiation of the third process. The third process is repeated for each trench of the diaphragm wall in the zone. After finishing the third process, the dummy queue, named "L04", and Combi logic activity, named "Logic04" with zero duration are used to create a lag between the third process and the fifth one. It should be noted that the lag is captured by setting a number of segments between those two processes. Similarly, the remaining fourth to seventh processes are modeled. The simulation model runs till the number of segments reaches a dummy queue "End" and it stops where there is no dummy resource to be initiated. More details about modeling tunnel construction using diaphragm walls, secant pile walls, steel sheet pile walls, TBM, micro tunneling are available elsewhere (Abdallah 2008; Marzouk et al. 2009).

An application example is considered to demonstrate the generated outputs from the Simulation Module. This example considers the construction of Giza tunnel project to solve a traffic jam problem through the elimination of a traffic light while converting the other traffic flow through an underground tunnel, as shown in Figure 6. The tunnel has a total length of 450 meters and a slightly varying width with an average of 8.5 meters, and secant pile walls technique was used in order to support ground while tunnel was being constructed, and also to act as the side supports of the tunnel. The tunnel has varying cross-section shapes including: retaining walls at the entrance and exit, U-section, and a box section in the middle; five zones were considered in order to account for these varying cross-section shapes (see Fig. 6). In order to model the Giza tunnel in the simulation module, project general data should be defined at the beginning, which includes working hours per day; working days per week and project start date. After that the project specific data should be fed to the module in order to simulate the tunnel and provide its results; these data include tunnel construction technique, task durations, number of equipment and crews to be used in the project, labor, equipment and material unit costs, and relationship between zones. Tunnel construction using secant pile walls include nine processes, while Table 4 shows an example for the input durations and resources data for three processes of the Giza tunnel. The relationships between zones can be defined throughout four relationships including FS, SS, SF, and FF; Figure 7 shows the relationships between these zones for the Giza tunnel. In order to facilitate data entry and show the output results of the simulation module, a user friendly tool was developed using Visual Basic 6.0. The output of Giza tunnel is shown in Figure 8. The output results of the simulation module were validated as they comply with the actual construction of the tunnel. More details about modeling, input data, and analysis of Giza tunnel are available elsewhere (Abdallah 2008).

\subsection{Decision support module}

Decision support module is responsible for selecting the best alternative of tunnel construction based on pre-defined criteria and a group of experts. Fuzzy techniques have been increasingly applied to construction management research area (Chan et al. 2009). The Fuzzy Logic tool was introduced in 1965, by Lotfi Zadeh, to provide a technique to deal with imprecision and information granularity. The fuzzy theory provides a mechanism for representing linguistic constructs, such as "many", "low", "medium", "often", "few". In general, the fuzzy logic provides an inference structure that enables appropriate human reasoning capabilities. Particular linguistic assessment terms, so called fuzzy linguistic variables, are introduced to represent the underlying fuzzy numbers for criteria evaluations. A fuzzy linguistic variable is defined as an expression in natural or artificial

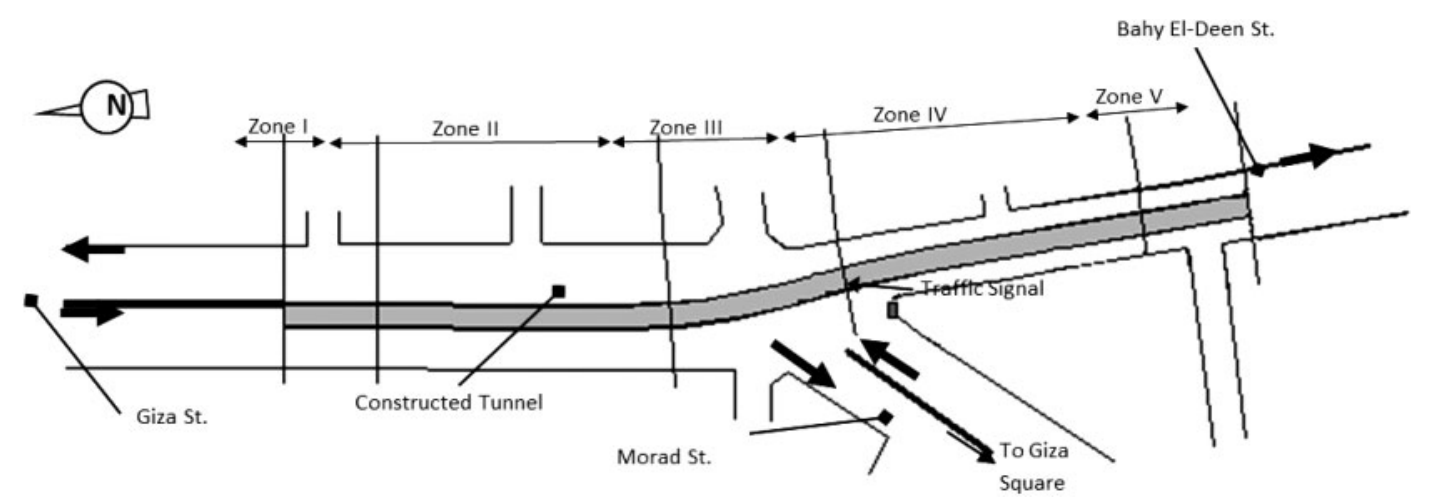

Fig. 6. Site layout of El-Giza tunnel (Marzouk et al. 2008b) 
Table 4. Task durations and resources of Giza tunnel

\begin{tabular}{|c|c|c|c|c|c|c|c|c|}
\hline \multirow[b]{2}{*}{ Process } & \multirow[b]{2}{*}{ Activity } & \multirow[b]{2}{*}{ Resources } & \multicolumn{2}{|c|}{ Zone II and IV } & \multicolumn{2}{|c|}{ Zone III } & \multicolumn{2}{|c|}{ Zone I and V } \\
\hline & & & No. & Duration & No. & Duration & No. & Duration \\
\hline \multirow{4}{*}{$\begin{array}{l}\text { Segment } \\
\text { preparation }\end{array}$} & Segment survey & Survey crew & 1 & $\mathrm{~N}(12,2) \mathrm{h}$ & 1 & $\mathrm{~N}(12,2) \mathrm{h}$ & 1 & $\mathrm{~N}(12,2) \mathrm{h}$ \\
\hline & $\begin{array}{l}\text { Locating and } \\
\text { temporary casing } \\
\text { installation }\end{array}$ & $\begin{array}{l}\text { Survey crew, pile } \\
\text { drilling rig }\end{array}$ & 1,1 & $\mathrm{~N}(10,2) \mathrm{m}$ & 1,1 & $\mathrm{~N}(10,2) \mathrm{m}$ & & \\
\hline & Drilling & Pile drilling rig & 1 & $\mathrm{U}(15,20) \mathrm{m}$ & 1 & $\mathrm{U}(15,20) \mathrm{m}$ & & \\
\hline & $\begin{array}{l}\text { Plastic concrete } \\
\text { pouring }\end{array}$ & $\begin{array}{l}\text { Crane, concrete } \\
\text { crew }\end{array}$ & 1,1 & $\mathrm{U}(20,25) \mathrm{m}$ & 1,1 & $\mathrm{U}(20,25) \mathrm{m}$ & & \\
\hline \multirow[t]{5}{*}{$\begin{array}{l}\text { Construction of } \\
\text { secant pile wall } \\
\text { (one pile) }\end{array}$} & $\begin{array}{l}\text { Locating and } \\
\text { temporary casing } \\
\text { installation }\end{array}$ & $\begin{array}{l}\text { Survey crew, pile } \\
\text { drilling rig }\end{array}$ & 1,1 & $\mathrm{U}(1.5,2) \mathrm{h}$ & 1,1 & $\mathrm{U}(1.5,2) \mathrm{h}$ & 0 & $\mathrm{~N}(0,0)$ \\
\hline & Drilling & Pile drilling rig & 1,1 & $\mathrm{U}(15,20) \mathrm{m}$ & 1,1 & $\mathrm{U}(15,20) \mathrm{m}$ & & \\
\hline & $\begin{array}{l}\text { Preparing and fixing } \\
\text { of steel cage }\end{array}$ & RFT crew & 1 & $\mathrm{U}(2.5,4) \mathrm{h}$ & 1 & $\mathrm{U}(2.5,4) \mathrm{h}$ & & \\
\hline & $\begin{array}{l}\text { positioning steel } \\
\text { cage into hole }\end{array}$ & Crane,RFT crew & 1,1 & $\mathrm{~N}(45,10) \mathrm{m}$ & 1,1 & $\mathrm{~N}(45,10) \mathrm{m}$ & & \\
\hline & Concrete pouring & $\begin{array}{l}\text { Concrete mixer, } \\
\text { concrete crew }\end{array}$ & 1,1 & $\mathrm{U}(1.5,2) \mathrm{h}$ & 1,1 & $\mathrm{U}(1.5,2) \mathrm{h}$ & & \\
\hline \multirow{8}{*}{$\begin{array}{l}\text { Construction of } \\
\text { one bottom slab } \\
\text { segment }\end{array}$} & $\begin{array}{l}\text { Excavation till the } \\
\text { base of bottom slab }\end{array}$ & Excavators & 2 & $\mathrm{U}(3,4) \mathrm{d}$ & 2 & $\mathrm{U}(3,4) \mathrm{d}$ & 1 & $\mathrm{~N}(1,0.5) \mathrm{d}$ \\
\hline & $\begin{array}{l}\text { Pouring plain } \\
\text { concrete between } \\
\text { the two sides of the } \\
\text { tunnel }\end{array}$ & $\begin{array}{l}\text { Concrete mixer, } \\
\text { concrete crew }\end{array}$ & 1,1 & $\mathrm{~N}(12,1) \mathrm{h}$ & 1,1 & $\mathrm{~N}(12,1) \mathrm{h}$ & 1,1 & $\mathrm{~N}(6,1) \mathrm{h}$ \\
\hline & $\begin{array}{l}\text { Water insulation for } \\
\text { one segment }\end{array}$ & Concrete crew & 1 & $\mathrm{U}(4,5) \mathrm{d}$ & 1 & $\mathrm{U}(4,5) \mathrm{d}$ & 0 & $\mathrm{~N}(0,0)$ \\
\hline & $\begin{array}{l}\text { Steel work for one } \\
\text { segment }\end{array}$ & RFT crews & 8 & $\mathrm{U}(2,3) \mathrm{d}$ & 8 & $\mathrm{U}(2,3) \mathrm{d}$ & 4 & $\mathrm{U}(1,1.5) \mathrm{d}$ \\
\hline & $\begin{array}{l}\text { Shuttering forms } \\
\text { and installing of } \\
\text { water stop (if exist) }\end{array}$ & Formwork crews & 4 & $\mathrm{~N}(12,2) \mathrm{h}$ & 4 & $\mathrm{~N}(12,2) \mathrm{h}$ & 2 & $\mathrm{~N}(1,0) \mathrm{d}$ \\
\hline & Concrete pouring & $\begin{array}{l}\text { Concrete mixer, } \\
\text { concrete pump, } \\
\text { concrete crew }\end{array}$ & $1,1,1$ & $\mathrm{~N}(10,2) \mathrm{h}$ & $1,1,1$ & $\mathrm{~N}(10,2) \mathrm{h}$ & $1,1,1$ & $\mathrm{~N}(8,2) \mathrm{h}$ \\
\hline & Concrete curing & - & 0 & $\mathrm{~N}(12,0) \mathrm{h}$ & 0 & $\mathrm{~N}(12,0) \mathrm{h}$ & 0 & $\mathrm{~N}(1,0) \mathrm{d}$ \\
\hline & Removal of forms & Formwork crews & 2 & $\mathrm{~N}(12,2) \mathrm{h}$ & 2 & $\mathrm{~N}(12,2) \mathrm{h}$ & 2 & $\mathrm{~N}(1,0) \mathrm{d}$ \\
\hline
\end{tabular}

$\mathrm{U}[\mathrm{a}, \mathrm{b}]$ : Uniform distribution; $\mathrm{a}$ is the lower value; $\mathrm{b}$ is the higher value.

$\mathrm{N}[\mathrm{a}, \mathrm{b}]$ : Normal distribution; $\mathrm{a}$ is the mean; $\mathrm{b}$ is the standard deviation.

$\mathrm{d}$, days; h, hours; $\mathrm{m}$, minutes.

language which describes a collection of values (Zadeh 1975; Cakir, Canbolat 2008).

The proposed decision support module uses fuzzy numbers for preferences of criteria in order to deal with the fuzziness of the decision maker preferences. Due to the subjective judgment of decision makers, a belief level was used to express the preferences of decision makers for each criterion within an alternative. This belief level belongs to a set of linguistic terms which contain various degrees of preferences. These linguistic terms and degrees of preferences include seven levels that are varying from "Very Low" to "Very High" and represented with triangular fuzzy numbers, as shown in Table 5. These degrees of preference can be used by decision makers to evaluate the different criteria under each alternative. This Decision Support method also aggregates the group decision in a manner that is most acceptable for the group as a whole The relative importance among decision makers can be determined based on the number of years of experience in the field of tunnel construction. Five levels that were set to account for relative importance among decision makers include "Less than 5 years", "5 years to 10 years", "10 years to 15 years", "15 years to 20 years", and "More than 20 years". These levels were represented by a quantitative scale (1, 2, 3, 4, and 5) respectively, where the normalized average weight can be determined. Similarly, the criteria weights can be determined using 


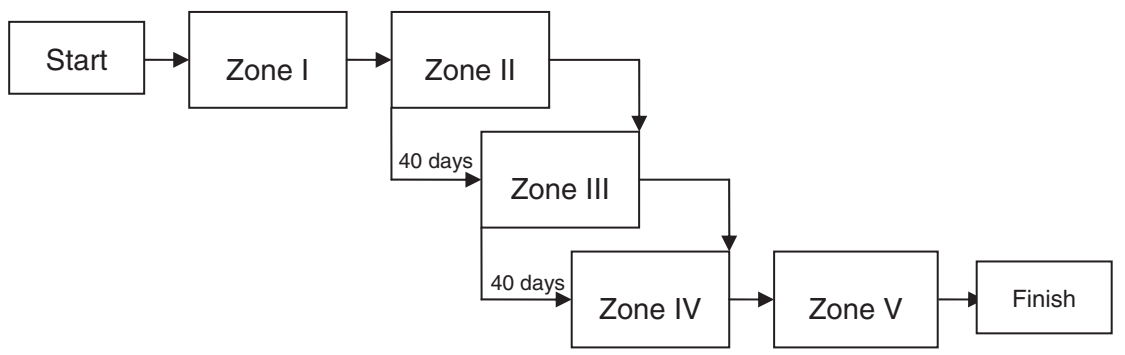

Fig. 7. Relationships among zones of Giza tunnel

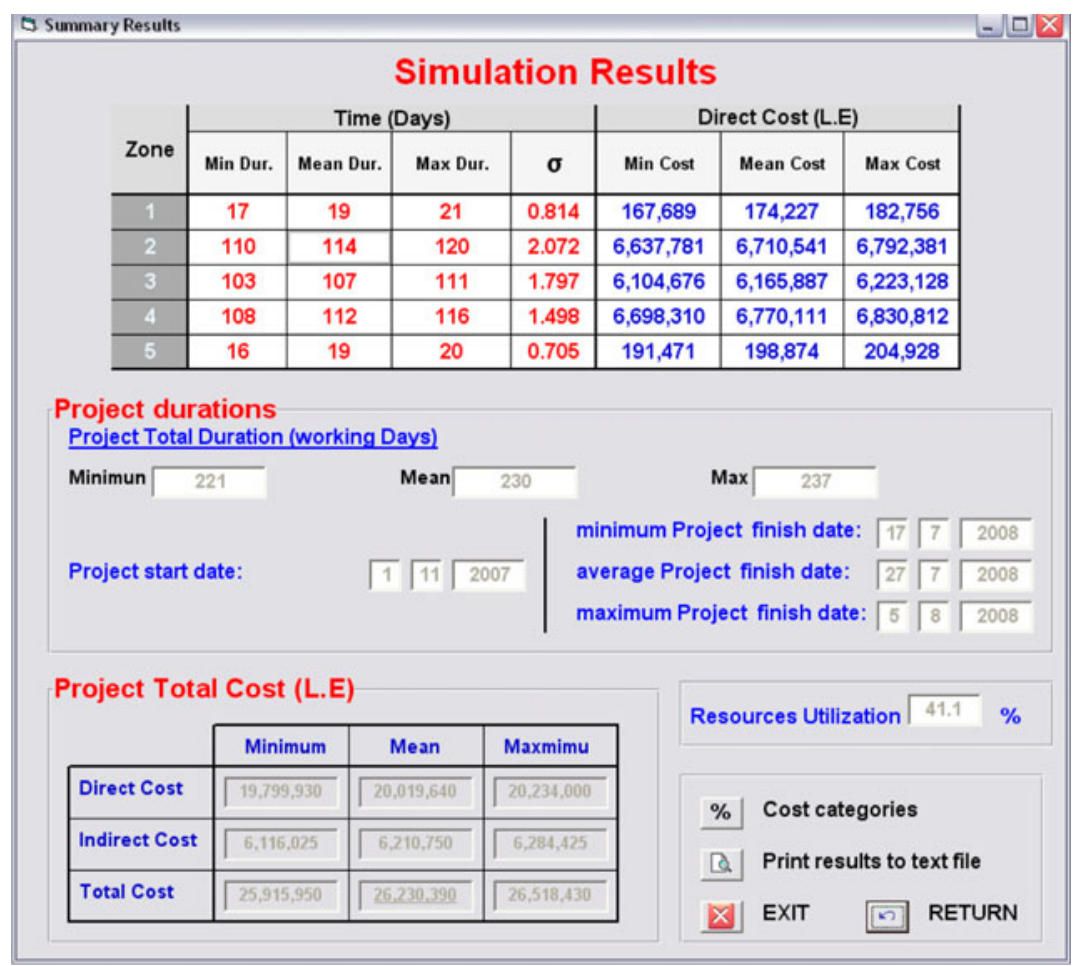

Fig. 8. Output results of the simulation module

Table 5. Triangular fuzzy numbers for criteria ranges

\begin{tabular}{lll}
\hline $\begin{array}{l}\text { Project cost and } \\
\text { duration }\end{array}$ & \multicolumn{1}{c}{$\begin{array}{c}\text { Resources' } \\
\text { utilization }\end{array}$} & $\begin{array}{c}\text { Triangular fuzzy } \\
\text { number }\end{array}$ \\
\hline $\begin{array}{l}\text { Very high (VH) } \\
\text { High (H) }\end{array}$ & Very low (VL) & $(0,0,0.1)$ \\
Medium high (MH) & Medium low (ML) & $(0,0.1,0.3)$ \\
Medium (M) & Medium (M) & $(0.3,0.3,0.5)$ \\
Medium low (ML) & Medium high (MH) & $(0.5,0.7,0.9)$ \\
Low (L) & High (H) & $(0.7,0.9,1)$ \\
Very low (VL) & Very high (VH) & $(0.9,1,1)$ \\
\hline
\end{tabular}

five level linguistic weights including "Very Important", "Rather Important", "Important", "Less Important", and "Unimportant". These levels were represented with quantitative scale $(1,2,3,4$, and 5), respectively, where the relative normalized weight among criteria can be computed for each decision maker (Zhang, Lu 2003). The procedures that are followed by the proposed framework for selecting the best alternative for tunnel construction can be listed as follows:

- Define selection criteria: experts define the requirements that each alternative must own, to be better or less important than other alternatives. The decision support module defines three main criteria: project cost, project duration, and resources utilization. These three main criteria are obtained from tunnel analyzer module. Decision support module can consider another two user-defined criteria to provide flexibility in selecting alternatives. These two criteria can be defined separately by the experts, such as utilization of a specific important resource. Also, criteria weights and expert years of experience are defined by each expert. Each criterion and expert years of experience are defined through five levels of importance; 
- Defining alternatives criteria: at this stage, the output data from tunnel analyzer module can be used to assign values for criteria of each alternative. These data include project cost, duration, and/or resources utilization. Also, each expert assigns preferences of criteria through three ranges low, medium and high;

- Ranking alternatives: alternatives are categorized based on the collected data and fuzzy group decision-making method to select the best alternative. The alternative with the highest preference value is considered as the best one;

- Refining selection: experts can refine results by ignoring alternatives with small far preference values or editing the selection criteria in the first stage.

Planning and analyzing tunnel construction using computer simulation have been demonstrated using case studies elsewhere (Marzouk et al. 2008b, 2009, 2010). The decision support module is explained in this paper via a numerical example to demonstrate its use. A contractor wants to select the best tunnel construction method among three possible construction alternatives. The tunnel under consideration has dimensions of $0.5 \mathrm{~km}$ in length and $10.5 \mathrm{~m}$ in width. Two experts are represented for selecting the best construction alternative. The first expert has an experience of 18 years in tunnel field, whereas the second expert has an experience of 8 years in the same field. They choose the basic three criteria, project cost, project duration, and utilization of resources, as the basic elements in selecting the best alternative. Table 6 lists the three criteria ranges for the two involved experts.

Criteria weights are leveled and listed by each expert in Table 7. The criteria values, project cost, project duration, and utilization of resources, for the three alternatives are listed in Table 8 .

To get the most acceptable solution among the three alternatives, the following steps are carried out (Zhang, Lu 2003).
Table 7. Experts' criteria levels

\begin{tabular}{ll}
\hline Expert A & \multicolumn{1}{c}{ Expert B } \\
\hline Very important & Rather important \\
Rather important & Rather important \\
Unimportant & Less important \\
\hline
\end{tabular}

Table 8. Criteria values for the three alternatives

\begin{tabular}{lll}
\hline Alternative I & Alternative II & Alternative III \\
\hline $26,230,395$ L.E. & $26,916,675$ L.E. & $25,197,130$ L.E. \\
230 days & 215 days & 293 days \\
$41.1 \%$ & $35.7 \%$ & $32 \%$ \\
\hline
\end{tabular}

Step 1. Table 9 lists criteria levels, scale and weights for each expert.

Step 2. After dividing the three criteria ranges defined in Table 6 into seven ranges, belief level matrixes can be established for alternatives as shown in Eqn (5):

Table 9. Criteria weights

\begin{tabular}{|c|c|c|c|c|}
\hline & Criterion & $\begin{array}{l}\text { Criterion } \\
\text { level }\end{array}$ & $\begin{array}{l}\text { Criterion } \\
\text { scale }\end{array}$ & $\begin{array}{c}\text { Criterion } \\
\text { weight }\end{array}$ \\
\hline \multirow[t]{3}{*}{$\begin{array}{l}\text { Expert } \\
\text { A }\end{array}$} & $\begin{array}{l}\text { Project cost } \\
\left(W_{1}^{1}\right)\end{array}$ & $\begin{array}{l}\text { Very } \\
\text { important }\end{array}$ & 5 & 0.5 \\
\hline & $\begin{array}{l}\text { Project } \\
\text { duration }\left(W_{2}^{1}\right)\end{array}$ & $\begin{array}{l}\text { Rather } \\
\text { important }\end{array}$ & 4 & 0.4 \\
\hline & $\begin{array}{l}\text { Resources } \\
\text { utilization }\left(W_{3}^{1}\right)\end{array}$ & Unimportant & 1 & 0.1 \\
\hline \multirow[t]{3}{*}{$\begin{array}{l}\text { Expert } \\
\text { B }\end{array}$} & $\begin{array}{l}\text { Project cost } \\
\left(W_{1}^{2}\right)\end{array}$ & $\begin{array}{l}\text { Rather } \\
\text { important }\end{array}$ & 4 & 0.4 \\
\hline & $\begin{array}{l}\text { Project } \\
\text { duration }\left(W_{2}^{2}\right)\end{array}$ & $\begin{array}{l}\text { Rather } \\
\text { important }\end{array}$ & 4 & 0.4 \\
\hline & $\begin{array}{l}\text { Resources } \\
\text { utilization }\left(W_{3}^{2}\right)\end{array}$ & $\begin{array}{l}\text { Less } \\
\text { important }\end{array}$ & 2 & 0.2 \\
\hline
\end{tabular}

$W_{i}^{j}$, weight for criterion " $i$," given by expert " $j$. ."

Table 6. Criteria ranges for experts

\begin{tabular}{llll}
\hline & Expert A & & Expert B \\
\hline Lower limit (L.E.) & Upper limit (L.E.) & Lower limit (L.E.) & Upper limit (L.E.) \\
$24,000,000$ & $25,000,000$ & $22,000,000$ & $24,000,000$ \\
$25,000,000$ & $26,000,000$ & $24,000,000$ & $26,000,000$ \\
$26,000,000$ & $27,000,000$ & $26,000,000$ & $28,000,000$ \\
Lower limit (days) & Upper limit (days) & Lower limit (days) & Upper limit (days) \\
150 & 200 & 175 & 225 \\
200 & 250 & 225 & 260 \\
250 & 300 & 260 & 320 \\
Lower limit (\%) & Upper limit (\%) & Lower limit (\%) & Upper limit (\%) \\
10 & 20 & 5 & 25 \\
20 & 40 & 25 & 45 \\
40 & 50 & 45 & 65 \\
\hline
\end{tabular}




$$
\begin{aligned}
& {\left[\begin{array}{lll}
b_{11}^{1} & b_{12}^{1} & b_{13}^{1} \\
b_{21}^{1} & b_{22}^{1} & b_{23}^{1} \\
b_{31}^{1} & b_{32}^{1} & b_{33}^{1}
\end{array}\right]=\left[\begin{array}{ccc}
\mathrm{ML} & \mathrm{M} & \mathrm{MH} \\
\mathrm{VL} & \mathrm{M} & \mathrm{MH} \\
\mathrm{MH} & \mathrm{VL} & \mathrm{M}
\end{array}\right]=\left[\begin{array}{ccc}
(0.1,0.3,0.5) & (0.3,0.5,0.7) & (0.5,0.7,0.9) \\
(0,0,0.1) & (0.3,0.5,0.7) & (0.5,0.7,0.9) \\
(0.5,0.7,0.9) & (0,0,0.1) & (0.3,0.5,0.7)
\end{array}\right]} \\
& {\left[\begin{array}{lll}
b_{11}^{2} & b_{12}^{2} & b_{13}^{2} \\
b_{21}^{2} & b_{22}^{2} & b_{23}^{2} \\
b_{31}^{2} & b_{32}^{2} & b_{33}^{2}
\end{array}\right]=\left[\begin{array}{ccc}
\mathrm{ML} & \mathrm{MH} & \mathrm{MH} \\
\mathrm{L} & \mathrm{MH} & \mathrm{M} \\
\mathrm{M} & \mathrm{L} & \mathrm{M}
\end{array}\right]=\left[\begin{array}{ccc}
(0.1,0.3,0.5) & (0.5,0.7,0.9) & (0.5,0.7,0.9) \\
(0,0.1,0.3) & (0.5,0.7,0.9) & (0.3,0.5,0.7) \\
(0.3,0.5,0.7) & (0,0.1,0.3) & (0.3,0.5,0.7)
\end{array}\right]}
\end{aligned}
$$

Step 3. Aggregating belief vectors. Table 10 lists belief vectors and their calculated values. Belief vector values are calculated for $\bar{b}_{1}^{1}$ and $\bar{b}_{2}^{1}$ as shown in Eqn (6):

$$
\begin{aligned}
\bar{b}_{1}^{1}= & w_{1}^{1} b_{11}^{1}+w_{2}^{1} b_{12}^{1}+w_{3}^{1} b_{13}^{1}=0.5 \cdot(0.1,0.3,0.5)+ \\
& 0.4 \cdot(0.3,0.5,0.7)+0.1 \cdot(0.5,0.7,0.9)= \\
& (0.22,0.42,0.62) ; \\
\bar{b}_{2}^{1}= & w_{1}^{1} b_{21}^{1}+w_{2}^{1} b_{22}^{1}+w_{3}^{1} b_{23}^{1}=0.5 \cdot(0,0,0.1)+ \\
& 0.4 \cdot(0.3,0.5,0.7)+0.1 \cdot(0.5,0.7,0.9)= \\
& (0.17,0.27,0.42)
\end{aligned}
$$

where: $\bar{b}_{j}^{i}$ is belief vector for a decision maker $i$ and alternative $j ; w_{k}^{i}$ - weight for a criterion $k$ and a decision maker $i$.

Step 4. The weight for each expert can be determined as per Table 11.

Step 5. Determination of fuzzy decision vectors. Table 12 lists the calculated values of fuzzy decision vector. For example $\tilde{r}_{1}$ and $\tilde{r}_{2}$ are calculated using values of belief vectors (listed in Table 9), experts' years of experience weight $\left(v_{1}^{*}\right.$ and $v_{2}^{*}$ which are listed in Table 10) as shown in Eqn (7):

$$
\begin{aligned}
\tilde{r}_{1}= & v_{1}^{*} \bar{b}_{1}^{1}+v_{2}^{*} \bar{b}_{1}^{2}=0.67 \cdot(0.22,0.42,0.62)+0.33 \\
& (0.34,0.54,0.74)=(0.26,0.32,0.49) \\
\tilde{r}_{2}= & v_{1}^{*} \bar{b}_{2}^{1}+v_{2}^{*} \bar{b}_{2}^{2}=0.67 \cdot(0.17,0.27,0.42)+0.33 . \\
& (0.26,0.42,0.62)=(0.20,0.32,0.49)
\end{aligned}
$$

Step 6. Calculating the fuzzy positive and negative solution distances. Table 13 lists the calculated values of solution distances. Solution positive $\left(d_{1}^{+}\right)$and negative $\left(d_{1}^{-}\right)$distances are calculated as shown in Eqn (8).

Step 7. Finally, calculation of closeness coefficient. Table 14 lists values of closeness coefficient.
Table 10. Values of belief vectors

\begin{tabular}{lc}
\hline Belief vector & Value \\
\hline $\bar{b}_{1}^{1}$ & $(0.22,0.42,0.62)$ \\
$\bar{b}_{2}^{1}$ & $(0.17,0.27,0.42)$ \\
$\bar{b}_{3}^{1}$ & $(0.28,0.4,0.56)$ \\
$\bar{b}_{1}^{2}$ & $(0.34,0.54,0.74)$ \\
$\bar{b}_{2}^{2}$ & $(0.26,0.42,0.62)$ \\
$\bar{b}_{3}^{2}$ & $(0.18,0.34,0.54)$ \\
\hline $\bar{b}_{j}^{i}$, belief vector for criterion “ $j$ " and decision maker " $i$ "'.
\end{tabular}

Table 11. Experts' years of experience weight

\begin{tabular}{lccc}
\hline Expert & $\begin{array}{c}\text { Years of } \\
\text { experience }\end{array}$ & $\begin{array}{c}\text { Expert } \\
\text { scale }\end{array}$ & $\begin{array}{c}\text { Expert } \\
\text { weight }\end{array}$ \\
\hline First Expert $\left(v_{1}^{*}\right)$ & 18 & 4 & 0.67 \\
Second Expert $\left(v_{2}^{*}\right)$ & 8 & 2 & 0.33 \\
\hline
\end{tabular}

Table 12. Calculated values of fuzzy decision vectors

\begin{tabular}{lc}
\hline Decision vector & Value \\
\hline$\tilde{r}_{1}$ & $(0.26,0.46,0.66)$ \\
$\tilde{r}_{2}$ & $(0.20,0.32,0.49)$ \\
$\tilde{r}_{3}$ & $(0.25,0.38,0.55)$ \\
\hline
\end{tabular}

Table 13. Values of solution distances

\begin{tabular}{lccc}
\hline $\begin{array}{l}\text { Belief } \\
\text { vector }\end{array}$ & $\begin{array}{c}\text { Positive } \\
\text { distances }\end{array}$ & $\begin{array}{c}\text { Belief } \\
\text { vector }\end{array}$ & $\begin{array}{c}\text { Negative } \\
\text { distances }\end{array}$ \\
\hline$d_{1}^{+}$ & $d\left(\tilde{r}_{1}, r^{+}\right)=0.564$ & $d_{1}^{-}$ & $d\left(\tilde{r}_{1}, r^{-}\right)=0.488$ \\
$d_{2}^{+}$ & $d\left(\tilde{r}_{2}, r^{+}\right)=0.675$ & $d_{2}^{-}$ & $d\left(\tilde{r}_{2}, r^{-}\right)=0.356$ \\
$d_{3}^{+}$ & $d\left(\tilde{r}_{3}, r^{+}\right)=0.62$ & $d_{3}^{-}$ & $d\left(\tilde{r}_{3}, r^{-}\right)=0.412$ \\
\hline
\end{tabular}

$$
\begin{aligned}
& d_{1}^{+}=d\left(\tilde{r}_{1}, r^{+}\right)=\sqrt{\frac{1}{3}\left[(1-0.26)^{2}+(1-0.46)^{2}+(1-0.66)^{2}\right]}=0.564 \\
& d_{1}^{-}=d\left(\tilde{r}_{1}, r^{-}\right)=\sqrt{\frac{1}{3}\left[0.26^{2}+0.46^{2}+0.66^{2}\right]}=0.488 .
\end{aligned}
$$


Table 14. Calculated values of closeness coefficients

\begin{tabular}{ll}
\hline Closeness coefficient & Value \\
\hline$C C_{1}$ & 0.462 \\
$C C_{2}$ & 0.34 \\
$C C_{3}$ & 0.397 \\
\hline
\end{tabular}

Closeness coefficient is calculated (e.g. $C C_{1}$ ) as shown in Eqn (9):

$$
\begin{aligned}
C C_{1}= & \frac{1}{2}\left(d_{1}^{-}+\left(1-d_{1}^{+}\right)\right)=\frac{1}{2}(0.488 \\
& +(1-0.564))=0.462
\end{aligned}
$$

From Table 12, $C C_{1}$ has the highest closeness coefficient, therefore, the best alternative based on the fuzzy decision-making method is the first one.

\section{Conclusions}

This paper presented a framework that aids contractors in planning tunnel projects using computer simulation. The proposed tool estimates time and cost required for construction of tunnels. Furthermore, it aids contractors to select the best alternative among a set of available alternatives in construction. This paper presented a framework that is able to model five techniques that are used in tunnel constructions. These techniques include: cut-and-cover using diaphragm walls, cut-and-cover using secant pile walls, cut-and-cover using soldier piles and lagging, cut-and-cover using steel sheet pile walls and segmental tunneling using slurry TBM. The proposed framework consists of three modules: tunnel analyzer module, simulation module, and decision support module. Tunnel analyzer module is considered as the coordinator of the decision support tool. It collects needed data for planning construction of tunnels. Simulation module is responsible for estimating total duration and utilization of resources in each zone of the tunnel. Five models for construction of tunnels have been coded in the simulation module to represent the different construction techniques. Simulation module receives its input data from tunnel analyzer module, where it generates an input file for each zone according to the utilized construction method. Then, it estimates construction duration of zone and utilization of resources. Decision support module is responsible for selecting the best construction alternative using a fuzzy group decision-making method. It selects the best alternative based on pre-defined criteria and a group of experts. It considers up to five criteria, three of them are considered main/basic criteria: project cost; project duration and utilization of resources, while, the remaining two criteria are defined by the user to allow more flexibility to the system. The decision support module analyzes alternatives to obtain the best construction option. A numerical example was presented in this paper to illustrate the main features of the decision support module.

\section{References}

Abdallah, M. 2008. Decision support tool for planning tunnels projects using computer simulation. MSc thesis. Structural Engineering Department, Cairo University, Egypt.

AbouRizk, S. M.; Er Ruwanpura, J. Y.; Fernando, K. C. 1999. Special purpose simulation template for utility tunnel construction, in Proc. of the 1999 Winter Simulation Conference, Phoenix, AZ, 948-955.

Al-Battaineh, H. T.; AbouRizk, S. M.; Tan, J.; Fernando, S. 2006. Productivity simulation during the planning phase of the Glencoe in Calgary, Canada: a case study, in Proc. of the 2006 Winter Simulation Conference, Monterey, CA, 2087-2092.

Alsugair, A. M. 1999. Framework for evaluating bids of construction contractors, Journal of Management in Engineering ASCE 15(2): 72-78. http://dx.doi.org/10.1061/(ASCE)0742-597X(1999) $15: 2(72)$

Banks, J.; Carson, J. S.; Nelson, B. L.; Nicol, D. M. 2000. Discrete-event system simulation. New Jersey, NJ: Prentice Hall. 640 p.

Deep Excavation. 2011. Sheet pile walls: retaining systems for deep excavation: sheet pile walls, deep excavation LLC [online], [cited 11 November 2011]. Available from Internet: http://www.deepexcavation.com/en/sheet-pilewalls.

Cakir, O.; Canbolat, M. S. 2008. A web-based decision support system for multi-criteria inventory classification using fuzzy AHP methodology, Expert Systems with Applications 35(3): 1367-1378.

http://dx.doi.org/10.1016/j.eswa.2007.08.041

Chan, A. P. C.; Chan, D. W. M.; Yeung, J. F. Y. 2009. Overview of the application of fuzzy techniques in construction management research, Journal of Construction Engineering and Management ASCE 135(11): 1241-1252.

http://dx.doi.org/10.1061/(ASCE)CO.1943-7862. 0000099

EOT, U.S.DOT. 2008. Technical Tunnel Alternatives summary Report Urban Ring Phase 2, Circumferential Transportation Improvements in the Urban Ring Corridor. Massachusetts Executive Office of Transportation (EOT), USA, U.S. Department of Transportation (U.S. DOT).

FORASOL. 2008. Secant Pile / Berliner Wall, Forasol Travaux Speciaux [online], [cited 11 August 2010]. Available from Internet: http://www.forasol.com/.

Halpin, D. W.; Riggs, L. S. 1992. Planning and analysis of construction operations. New York, NY: John Wiley \& Sons. $400 \mathrm{p}$.

Hassan, M. M.; Gruber, S. 2008. Simulation of concrete paving operations on Interstate -74, Journal of Construction Engineering and Management ASCE 134(1): $2-9$. http://dx.doi.org/10.1061/(ASCE)0733-9364(2008) 134:1(2) 
Henery Drilling. 2011. Soldier pile and lagging walls. Henery Drilling: specialized contractor in all types of drilled deep foundations and drilled earth retention systems [online], [cited 11 November 2011]. Available from Internet: http://henrydrilling.com/Soldier_pile_walls. html.

Keeney, R. L.; Raiffa, H. 1993. Decisions with multiple objectives: preferences and the value tradeoffs. New York: Cambridge University Press. 592 p.

Land Transport Authority. 2004. Construction of contiguous bored pile walls [online]. Land Transport Authority [cited 11 November 2011]. Available from Internet: http:// www.lta.gov.sg/projects/images/CBP\%20Final.pdf.

Lee-Kwang, H.; Lee, J.-H. 1999. A method for ranking fuzzy numbers and its application to decision making, IEEE Transactions on Fuzzy Systems 7(6): 677-684. http://dx.doi.org/10.1109/91.811235

Loannou, P. G.; Likhitruangslip, V. 2005. Simulation of multiple-drift tunnel construction with limited resources, in Proc. of the 2005 Winter Simulation Conference, Orlando, FL, 1483-1491.

Martinez, J. C. 1996. STOBOSCOPE, State and resource based simulation of construction processes. $\mathrm{PhD}$ thesis. University of Michigan, USA.

Marzouk, M. 2002. Optimizing earthmoving operations using computer simulation. $\mathrm{PhD}$ thesis. Department of Building, Civil, and Environmental Engineering, Concordia University, Canada.

Marzouk, M. 2008. A superiority and inferiority ranking model for contractor selection, Construction Innovation: Information, Process, Management 8(4): 250-268. http://dx.doi.org/10.1108/14714170810912644

Marzouk, M. 2010. The state of computer simulation applications in construction, in Abu-Taieh, E. M. O.; El Sheikh, A. A.; (Eds.). Handbook of research on discrete event simulation environments: technologies and applications. Pennsylvania, PA: IGI Global, 1554-1575.

Marzouk, M. M. 2011. ELECTRE III model for value engineering applications, Automation in Construction 20(5): 596-600.

http://dx.doi.org/10.1016/j.autcon.2010.11.026

Marzouk, M.; Zein, H.; El-Said, M. 2006. BRIGE_SIM: framework for planning and optimizing bridge deck construction using computer simulation, in Proc. of the 2006 Winter Simulation Conference, Monterey, CA, 2039-2046.

Marzouk, M.; Said, H.; El-Said, M. 2008a. Special purpose simulation model for balanced cantilever bridges, Journal of Bridge Engineering ASCE 13(2): 122-131. http://dx.doi.org/10.1061/(ASCE)1084-0702(2008) 13:2(122)

Marzouk, M.; Abdallah, M.; El-Said, M. 2008b. Tunnel_Sim: decision support tool for planning tunnel construction using computer simulation, in Proc. of the 2008 Winter Simulation Conference, Miami, FL, 25042511.

Marzouk, M.; Abdallah, M.; El-Said, M. 2009. A computer simulation model for cut and cover tunneling using secant pile walls, Arab Construction World (ACW) Magazine 27(3): 18-20.

Marzouk, M.; Abdallah, M.; El-Said, M. 2010. Modeling microtunneling projects using computer simulation,
Journal of Construction Engineering and Management ASCE 136(6): 670-682.

http://dx.doi.org/10.1061/(ASCE)CO.1943-7862. 0000169

McIntyre, C.; Kirschenman, M.; Seltveit, S. 1999. Applying decision support software in selection of division director, Journal of Construction Engineering and Management ASCE 15(2): 86-92.

http://dx.doi.org/10.1061/(ASCE)0742-597X(1999) $15: 2(86)$

Modarres, M.; Shadi-Nezhad, S. 2001. Ranking fuzzy numbers by preference ratio, Fuzzy Sets and Systems 118(3): 429-436. http://dx.doi.org/10.1016/S0165-0114(98)00427-8

Nishizaki, I.; Seo, F. 1994. Interactive support for fuzzy trade-off evaluation in group decision-making, Fuzzy Sets and Systems 68(3): 309-325. http://dx.doi.org/10.1016/0165-0114(94)90186-4

Saaty, T. L. 1980. The analytic hierarchy process: planning, priority setting, resource allocation. New York: McGraw Hill. 287 p.

Saaty, T. L. 1982. Decision making for leaders: the analytical hierarchy process for decisions in a complex world. Belmont, CA: Wadsworth. 292 p.

Seo, S.; Aramaki, T.; Hwang, Y.; Hanaki, K. 2004. Fuzzy decision-making tool for environmental sustainable buildings, Journal of Construction Engineering and Management ASCE 130(3): 415-423.

http://dx.doi.org/10.1061/(ASCE)0733-9364(2004) 130:3(415)

Singh, D.; Tiong, R. L. K. 2005. A fuzzy decision framework for contractor selection, Journal of Construction Engineering and Management ASCE 131(1): $62-70$.

http://dx.doi.org/10.1061/(ASCE)0733-9364(2005) 131:1(62)

Skibniewski, M. J.; Chao, L.-C. 1992. Evaluation of advanced construction technology with AHP method, Journal of Construction Engineering and Management ASCE 118(3): 577-593.

http://dx.doi.org/10.1061/(ASCE)0733-9364(1992) 118:3(577)

Tanaka, Y. 1993. Cycle time simulation of shield-tunneling operation, in Proc. of the 5th International Conference on Computing in Civil and Building Engineering, ASCE, Reston, USA, 1386-1389.

Xu, X. 2001. The SIR method: a superiority and inferiority ranking method for multiple criteria decision making, European Journal of Operational Research 131(3): 587602.

http://dx.doi.org/10.1016/S0377-2217(00)00101-6

Zadeh, L. A. 1975. The concept of a linguistic variable and its application to approximate reasoning, Information Sciences, Part I 8: 199-249. http://dx.doi.org/10.1016/0020-0255(75)90036-5

Zhang, G.; Lu, J. 2003. An integrated group decision making method dealing with fuzzy preferences for alternatives and individual judgments for selection criteria, Group Decision and Negotiation 12(6): 501515 .

http://dx.doi.org/10.1023/B:GRUP.0000004197 .04668.cf 
Moatassem ABDALLAH. Research assistant at Civil and Environmental Engineering, University of Illinois at Urbana Champaign, Illinois, USA. He received his BSc and MSc in structural engineering from Cairo University in 2005 and 2008, respectively. Currently, he is a PhD candidate at Civil and Environmental Engineering, University of Illinois at Urbana Champaign. His research interests include simulation, decision support systems, construction technology, automation in construction, life cycle costs, construction optimization, sustainability in construction, and optimizing upgrade decisions for sustainable buildings.

Mohamed MARZOUK. Associate Professor at Department of Structural Engineering, Faculty of Engineering, Cairo University. He received his BSc and MSc in Civil Engineering from Cairo University in 1995 and 1997 , respectively. He received his $\mathrm{PhD}$ form Concordia University in 2002. His research interests include simulation and optimization of construction processes, O-O simulation, fuzzy logic and its applications in construction, risk analysis, and decision analysis. 